\title{
Mortality risk factors in term and preterm infants with septic shock: A retrospective study
}

N. Vandewynckele ${ }^{1 *}$, L. Morin ${ }^{1}$, C. Dubois ${ }^{1}$, N. Le Sache ${ }^{1}$, M. Mokhtari ${ }^{1}$, P. Tissieres ${ }^{1}$.

${ }^{1}$ Paris South University Hospitals - Bicetre site, Neonatal intensive care unit, Le Kremlin Bicetre, France.

*Corresponding author: nada.semaan@aphp.fr, Tel: +33145213205

\section{Background \& Objective}

Neonatal sepsis is the third cause of death in neonatal intensive care unit (NICU) ${ }^{2}$, meanwhile septic shock in preterm and term infant has not been well studied. The main objective of this retrospective study was to identify mortality risk factor in term and preterm neonates during septic shock.

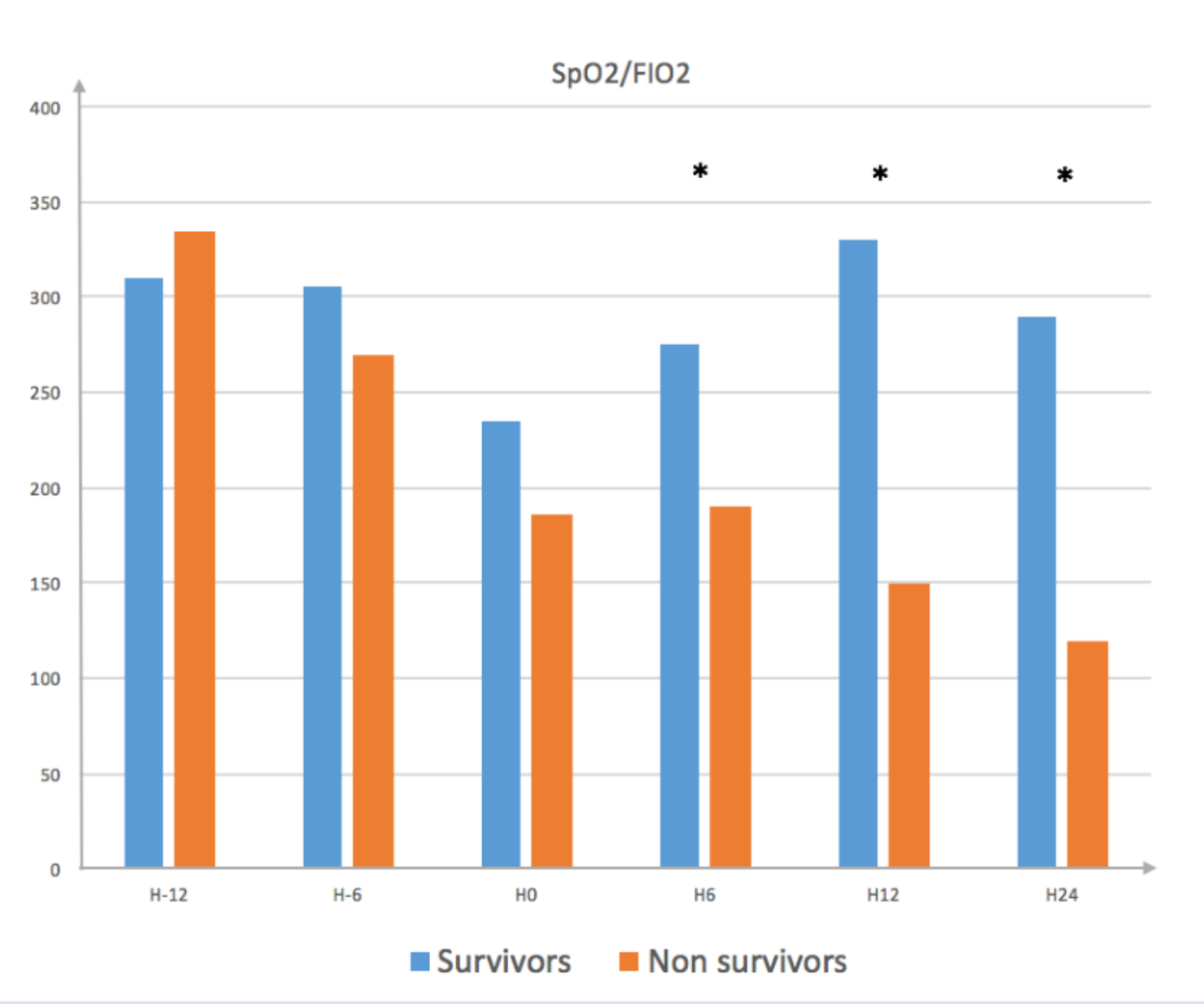

\section{Methods}

Preterm and term infant $<28$ days of life with septic shock were included in a 5-year's period in the NICU of Bicetre hospital in France. Respiratory, hemodynamic and renal failures were assessed at different timepoints before and after initiation of vasoactive therapies during $48 \mathrm{~h}$.

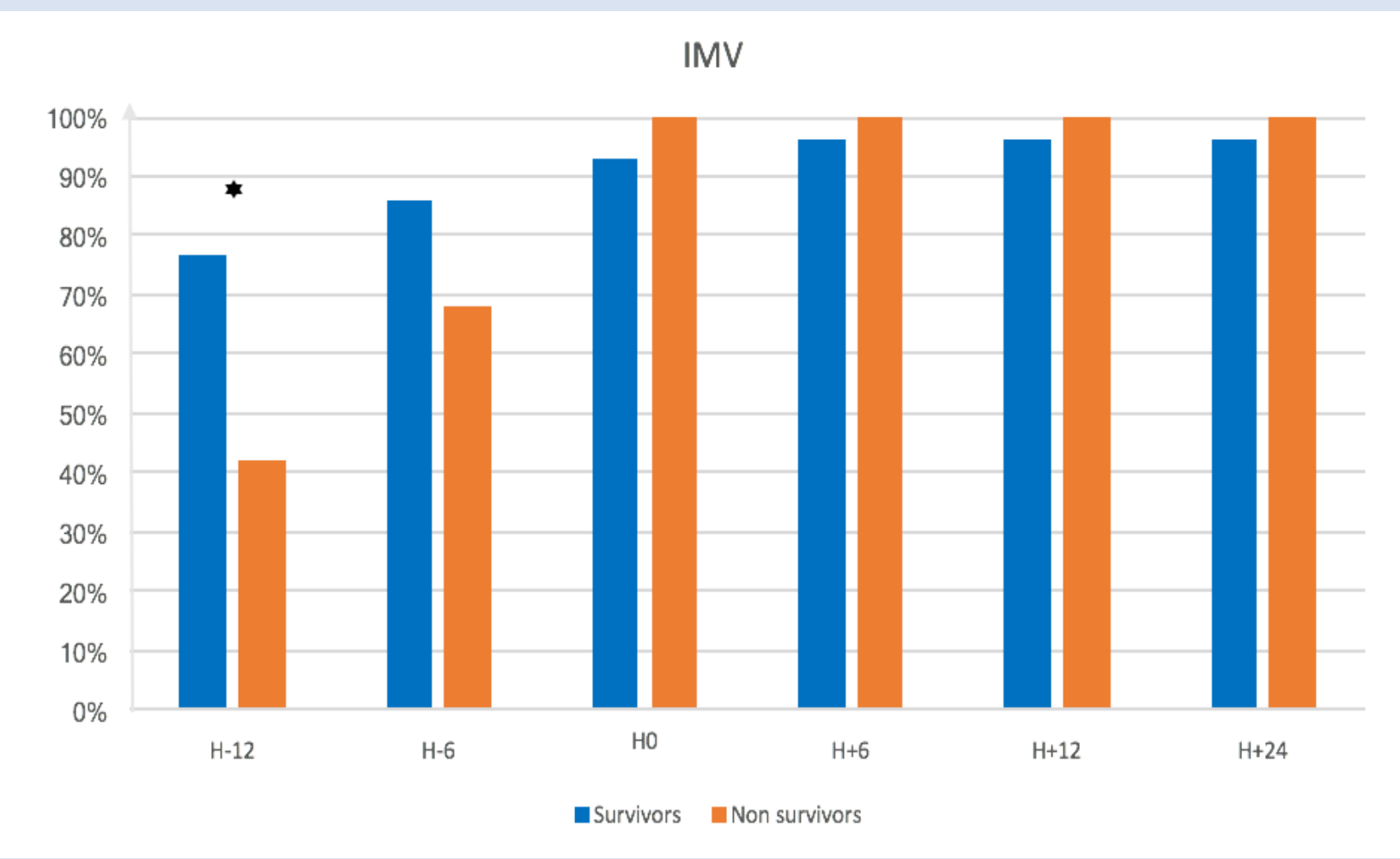

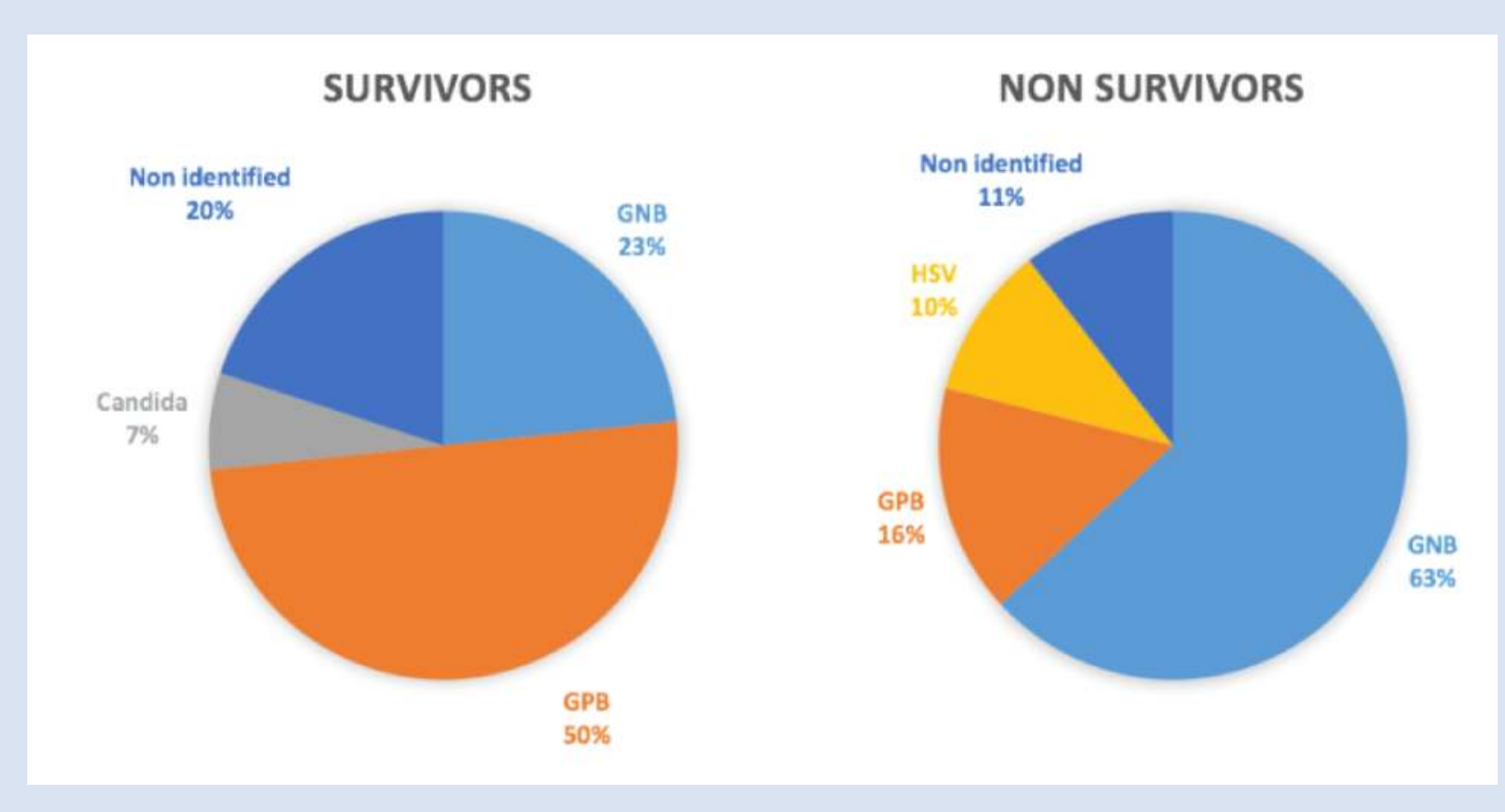

Results

Among 2139 patients, 49 (2.2\%) had septic shock with a mortality of $19 / 49$ (38\%). Gram negative infection was an independent risk of mortality (OR 7.7 95\% IC:1.1-51). $\mathrm{SpO} 2 / \mathrm{FiO} 2$ was decreased in non-survivors than in survivors at $\mathrm{H}+6$ (190 versus $275 \mathrm{p}=0.02), \mathrm{H}+12(150$ versus $330, \mathrm{p}<0.01)$ and $\mathrm{H}+24(120$ versus $290, \mathrm{p}<0.01)$. Use of invasive mechanical ventilation at $\mathrm{H}-12$ was decreased in non-survivors than in survivors ( $42 \%$ versus $77 \%, \mathrm{p}=0.01)$. Lactate was increased in non-survivors than in survivors at $\mathrm{H} 0(8 \mathrm{mmol} / 1$ versus $3.2 \mathrm{mmol} / \mathrm{l}$, $\mathrm{p}<0.01)$ and $\mathrm{H}+24(5.5 \mathrm{mmol} / \mathrm{l}$ versus $2 \mathrm{mmol} / \mathrm{l} \mathrm{p}<0.01)$. Adapted cSSS (computed septic shock score) was increased in non-survivors than in survivors at $\mathrm{H} 0(3.17$ versus $2.36 \mathrm{p}<0.01)$ and $\mathrm{H}+24(2.89$ versus $2.24 \mathrm{p}<0.01)$.

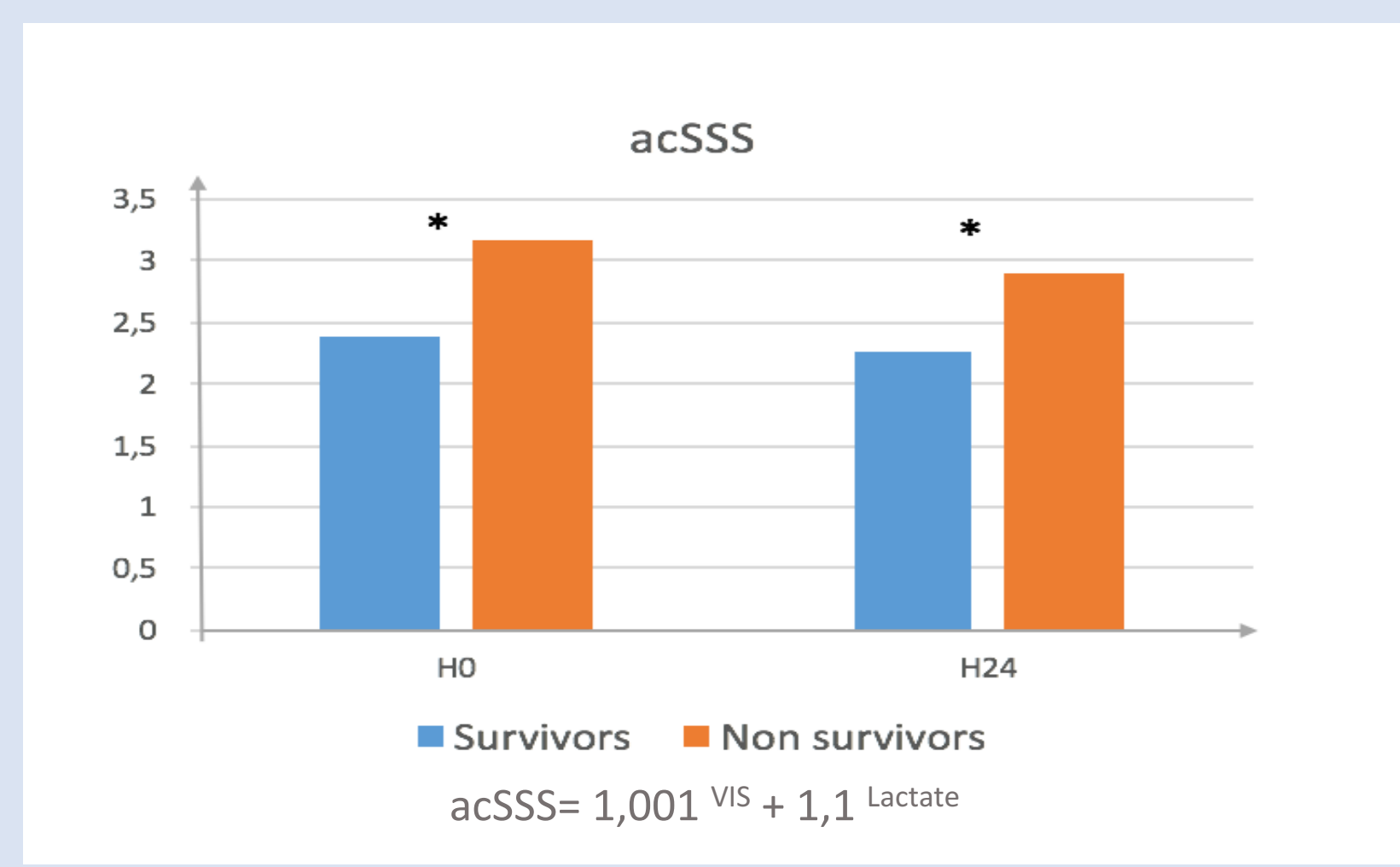

\section{Conclusion}

This study showed that gram negative pathogens was independently associated with mortality. $\mathrm{SpO} 2 / \mathrm{FiO} 2$ was decreased, lactate and adapted cSSS were increased in non-survivors than in survivors. Early invasive mechanical ventilation (IMV) was increased in survivors with septic shock 